\title{
Knowledge, Attitude and Practice of Cigarette Smoking among Male Students of Taibah University, Al Madinah, Saudi Arabia
}

\author{
Abdullah Alrehaili ${ }^{1}$, Alaa Felemban ${ }^{2}$, Walaa Felemban ${ }^{3}$, Abdullah Al-harbi $^{4}$, Yousef Ekhmimi ${ }^{5}$ \\ Supervisor Dr. Khaled Kasim, Ph.D. Epidemiology
}

\begin{abstract}
Tobacco use is one of the most common causes of cardiovascular, respiratory diseases and cancers. The aim of this study is to estimate the prevalence, knowledge and attitude toward cigarette smoking among university students of Taibah University, Madinah, Saudi Arabia. The present cross sectional study included 360 students from six faculties using a stratified random sampling procedure. The questionnaire was anonymous, self-written and adopted from Global Adult Tobacco Survey (GATS). A total of 342 out of 360 students enrolled in this study were analyzed. Seventy five students (21.9\%) indicated that they smoke tobacco at the time of the study while the percent of students who had ever smoked a cigarette even once during lifetime was 33.3\%.Cigarette smoking was practiced by the final years students more than first and second-year students with statistically significant difference (p=0.04). About 93.3\% of the students indicated that smoking could cause serious diseases, and $71.1 \%$ thought that smoking should be banned in public areas. The findings of this study confirm similar smoking prevalence among University students and indicate a higher percent of good knowledge and favorable attitude of the studied students towards cigarette smoking
\end{abstract}

Keywords: Attitude, Prevalence, Smoking, Students, Saudi Arabia

\section{Introduction}

Tobacco use is one of the most common causes of cardiovascular, respiratory diseases and cancers and is considered as an air pollutant which makes the rate of morbidity and mortality necessarily high among the population in all over the world. $(1,2)$. Based on World Health Organization (WHO), Tobacco use continues to be the leading global cause of preventable death killing nearly 6 million people worldwide each year. More than five million of those deaths are the result of direct tobacco use while more than 600,000 are the result of non-smokers being exposed to second-hand smoke . If the current trends continue the same, WHO expected that by 2030 tobacco smoking will kill more than 8 million of population worldwide each year $(2,3)$. In addition, tobacco use causes hundreds of billions of dollars of economic damage worldwide each year $(2,3)$,knowing that, the last prevalence of smokers was $37 \%$ which was estimated in Jeddah (4).In a school-based study conducted during 2013 among 3400 intermediate and secondary schools' students (11-19 years) in Madinah, Saudi Arabia using the global tobacco youth survey (GTYS) showed that prevalence of cigarette smoking was $15.17 \%$ (5).

Unless urgent action is taken, smoking is a behavior that can be accepted during the childhood period, if the children accept it, it can persist the whole life including the adolescence and University period. Most people already know that smoking is bad for their health, but do they really understand just how dangerous smoking really is. The available literature showed a gap in Saudi, particularly in Al-Madinah City, about knowledge, attitude and prevalence of smoking among University students. From this point, the aim of this study is to estimate the prevalence of smoking among students of Taibah University and to measure the knowledge and attitude of these students towards cigarettes smoking.

\section{Methodology}

This cross-sectional study was conducted among male students of faculties in Taibah University, Madinah, Saudi Arabia, from October to December 2016.

The study was carried out in a stratified random sampling procedure. The faculties were stratified into (i) faculties of health sciences; in which two out of five faculties were selected, and (ii) non-health faculties; in which four out of eleven faculties were selected.

The chosen faculties of each stratum were sub-stratified into two levels; first and second-years students and final years $\left(3^{\text {rd }}\right.$ and $4^{\text {th }}$ years) students, in which only one class was selected of each substratum. The final sampling units of each selected stratum at both levels were selected in a simple random way.

The calculated sample size for this study was obtained, using sample size formula, to be about 340 students. Knowing that, the last prevalence of cigarette smoking in Madinah study (5) was $15.17 \%$, an assumed precision of 0.05 and confidence interval of $99 \%$.

The data of the study was collected through a self-written questionnaire which was mainly adopted from Global Adult Tobacco Survey (GATS). This survey has been developed by many organizations and institutes including World Health Organization (WHO) and Centers of Disease Control and Prevention (CDC), and was designed to assess major issues related to cigarette smoking. The validity of the questions could be assumed as the same questionnaire has been used in many previous studies, in addition to the validation of the developing institutes $(6,7)$. The questionnaire has translated into Arabic language, and had been modified according to the local culture and religion. Back translation was done by another researcher to ensure accuracy. The questionnaire included 32 core questions related to social and smoking 


\section{International Journal of Science and Research (IJSR) \\ ISSN (Online): 2319-7064 \\ Index Copernicus Value (2015): 78.96 | Impact Factor (2015): 6.391}

status, as well as the knowledge and attitude towards cigarette smoking.

Smoking prevalence was defined as the percentage of current smokers among the university students. The standard National Survey on Drug Use (NSDUH-S) defined Current smokers as students who have smoked cigarettes on one or more days during the 1-month period before the survey was administered. A student who answered "yes" to the question "Beyond the 1-month period, have you ever tried smoking a cigarette?" was defined as "ever smoked", while students answering "no" were defined as "never smoked"(8).

Both never and ever smoked, also named as "ex-smoker" were combined and defined as "non-smoker" and the current smokers were simply the "smoker" in this study.

Data were entered and analyzed using the Statistical Package for Social Sciences (SPSS).Descriptive analysis was done to summarize information by calculating the number and percent for categorical variables, whereas the mean and standard deviation (SD) were calculated for continuous variables. Chi-squared test was used to measure difference in the prevalence of smoking between different groups of students. $\mathrm{P}$ values less than 0.05 was considered an indicator for statistically significant differences.

The survey was conducted with permission from Taibah University. We received an approval from the faculty of medicine and from the dean of each selected faculty. As there have been no invasive procedure would be used, only verbal consent was taken from the participated students after explaining the purpose of the study and highlighting that surveys would be anonymous and data would be kept confidential during handling and storage.

\section{Results}

A total number 342 out of 380 students were completed and return back the study questionnaire with an overall response rate of $90 \%$. The mean age of the analyzed students was $21.08 \pm 1.5$ years. All the studied students were male, of whom 329 (96.2\%) were single, while 12 of them $(3.5 \%)$ were married. Other characteristics of the studied students are shown in table (1).

Table 1: Characteristics of the studied students

\begin{tabular}{|l|c|c|}
\hline Characteristics & No. & $\%$ \\
\hline Marital status & 329 & $96.2 \%$ \\
- Single & 12 & $3.5 \%$ \\
- Married & 181 & $52.9 \%$ \\
\hline Study year & 161 & $47.1 \%$ \\
- Juniors & & \\
- Seniors & 274 & $80.8 \%$ \\
\hline Monthly income & 65 & $19.2 \%$ \\
- Reward only & & \\
- Reward and extra sources & 218 & $63.93 \%$ \\
\hline Faculty & 123 & $36.07 \%$ \\
- Non-health professional \\
- Health professional
\end{tabular}

Seventy five students $(21.9 \%)$ indicated that they used to smoke tobacco in the 30-days before the time of the study.
The mean age of smoking initiation among these students was $17.1 \pm 1.9$ years, with a range of 18 to 26 years. The mean number of cigarette smoked by daily smokers was $18.4 \pm 7.8$ while the range was from 1 to 40 cigarettes smoked daily. The students smoked more than 20 cigarettes per day were 30 students $(62.5 \%)$. More details about the prevalence of smoking in the studied students are presented in table 2 .

Table 2: Distribution of students by smoking status

\begin{tabular}{|l|c|c|}
\hline & No. & $\%$ \\
\hline Current Smoker & $\mathbf{7 5}$ & $\mathbf{2 1 . 9 \%}$ \\
- Occasional & 27 & $7.9 \%$ \\
- Daily & 48 & $14 \%$ \\
\hline Ex- smoker & $\mathbf{3 9}$ & $\mathbf{1 1 . 4 \%}$ \\
- Regular & 17 & $5 \%$ \\
- Try-out & 22 & $6.4 \%$ \\
\hline Never smoked & $\mathbf{2 2 7}$ & $\mathbf{6 6 . 4 \%}$ \\
\hline
\end{tabular}

The smokers among health sciences faculties were 24 (32\%) while among non-health sciences faculties were 51 students. About $96.2 \%$ of them were single, while $3.5 \%$ were married. The differences between other characteristics of smokers and non-smokers (ex-smokers + never smokers) are shown in Table (3).

Table 3: Comparison of smoking status by students' characteristics

\begin{tabular}{|l|c|c|c|}
\hline Characteristics & $\begin{array}{c}\text { Smokers } \\
n(\%)\end{array}$ & $\begin{array}{c}\text { Non-smokers } \\
n(\%)\end{array}$ & P value \\
\hline $\begin{array}{l}\text { Marital status } \\
\text { - Single }\end{array}$ & $\begin{array}{c}72(22 \%) \\
\text { - Married }\end{array}$ & $\begin{array}{c}256(78 \%) \\
9(75 \%)\end{array}$ & 0.70 \\
\hline $\begin{array}{l}\text { Study year } \\
\text { - Juniors }\end{array}$ & $32(17.7 \%)$ & $149(82.3 \%)$ & $0.04 *$ \\
- Seniors & $43(26.9 \%)$ & $117(73.1 \%)$ & \\
\hline $\begin{array}{l}\text { Monthly income } \\
\text { - Reward only }\end{array}$ & $61(22.3 \%)$ & $213(77.7 \%)$ & 0.07 \\
- Reward and extra sources & $13(20.3 \%)$ & $51(79.7 \%)$ & \\
\hline $\begin{array}{l}\text { Faculty } \\
\text { - Health sciences }\end{array}$ & $24(19.5 \%)$ & $99(80.5 \%)$ & 0.40 \\
- Non-health sciences & $51(23.4 \%)$ & $167(76.6 \%)$ & \\
\hline
\end{tabular}

*Significant

Two hundred forty three students $(71.1 \%)$ thought that smoking should be banned in public areas. The number of students thought that smoking could cause serious diseases was about $319(93.3 \%)$ while 7 students $(2 \%)$ thought it doesn't cause such serious health problem. As shown in table 4, studied students also indicated that the smoking could cause lung cancer and heart attack, but to lesser extent, to cerebral stroke, as $31.6 \%$ of the students did not know if smoking could cause cerebral stroke. The percentage of smokers thought that smoking causes serious diseases were about $82.7 \%$.

Table 4: Students' knowledge about smoking and diseases

\begin{tabular}{|l|c|c|c|}
\hline & $\begin{array}{c}\text { Yes } \\
\mathrm{n}(\%)\end{array}$ & $\begin{array}{c}\text { No } \\
\mathrm{n}(\%)\end{array}$ & $\begin{array}{c}\text { Don't know } \\
\mathrm{n}(\%)\end{array}$ \\
\hline Serious diseases & $319(93.3 \%)$ & $7(2 \%)$ & $11(3,2 \%)$ \\
\hline Cerebral stroke & $193(56.4 \%)$ & $36(10.5 \%)$ & $108(31.6 \%)$ \\
\hline Heart attack & $253(74 \%)$ & $15(4.4 \%)$ & $69(20.2 \%)$ \\
\hline Lung cancer & $305(89.2 \%)$ & $7(2 \%)$ & $25(7.3 \%)$ \\
\hline
\end{tabular}

The percent of all studied students who thought that smoking makes people more attractive were about $16.4 \%$, while the 


\section{International Journal of Science and Research (IJSR) \\ ISSN (Online): 2319-7064}

Index Copernicus Value (2015): 78.96 | Impact Factor (2015): 6.391

smokers who thought that smoking makes people more attractive were about $18.7 \%$. Also, all the studied students who thought that smokers had more friends were about $25.1 \%$, while the smokers who thought that smokers had more friends were about $21.3 \%$. The whole students who thought that smoker had less friends were about $34.8 \%$ while the smokers who thought that smokers had less friends were about $25.3 \%$. About $50.6 \%$ of the studied students have negative view for smokers, while $4.5 \%$ have positive view for them and $44.8 \%$ think there is no difference between smokers and non-smokers. Most of the smokers $(72.6 \%)$ thought there is no difference between themselves and non-smokers. The positive and negative view of the students as well as smokers and non smokers are presented in Table 5.

Table 5: Students' opinions about smokers

\begin{tabular}{|l|c|c|c|}
\hline & $\begin{array}{c}\text { Negative view } \\
\%\end{array}$ & $\begin{array}{c}\text { Positive view } \\
\%\end{array}$ & $\begin{array}{c}\text { No difference } \\
\%\end{array}$ \\
\hline All students & $50.6 \%$ & $4.5 \%$ & $44.8 \%$ \\
\hline Smokers & $19.2 \%$ & $8.2 \%$ & $72.6 \%$ \\
\hline Non smokers & $59.4 \%$ & $3.5 \%$ & $37.1 \%$ \\
\hline
\end{tabular}

The percent of smoker students that have smoking parents were about $68 \%$.On the other hand, the non-smoker students that have smoking fathers were about $35.7 \%$ with statistically significant difference $(\mathrm{p}<.0001)$ as presented in Table 6 .

Table 6: Parental smoking status and students' smoking status

\begin{tabular}{|c|c|c|c|}
\hline Student smoking & Smoking Father & Non-smoking Father & P value \\
\hline Smokers & $68 \%$ & $32 \%$ & \\
\hline Non-smokers & $35.7 \%$ & $64.3 \%$ & $<.0001^{*}$ \\
\hline
\end{tabular}

*significant

\section{Discussion}

Our study showed that the total percentage of students who had ever smoked a cigarette was $33.3 \%$. The percentage of students who are currently smoking was $21.9 \%$.The findings of this study confirm similar smoking prevalence among high schools and Universities students in other region and cities in Saudi Arabia. A high prevalence of adolescent and young adult smoking was also reported in recent Saudi studies conducted in Jeddah (4) and Riyadh $(8,9)$. The reported prevalence rates in those studies were $37 \%, 29.0 \%$ and $31.0 \%$, respectively, with a significant higher prevalence of smoking among male compared to female students in a study conducted in Riyadh study (8).

In comparison between senior year students and junior year students Tobacco smoking was found to be significantly higher among the former group. Previous studies conducted at Saudi Arabia have been reported the same findings regarding age group (10). This is probably due to increased stress faced by the students with their progression, over the years.

The present study showed that parental history of smoking was found to be a significant risk factor for tobacco use among students. Similarly in several studies, parental smoking was an important risk factor in adolescents' and young adults' smoking $(4,8,9,11)$ and international studies $(12,13)$. As most of youths look up to their parents and other close relatives in their society and attempt to mimic their demeanor, parents smoking showed to be the most important factor related to adolescents and young adults smoking in this and other studies (5) .

The smoker among the student were clearly familiar with impact of smoking on their health and the fact that the leading cause of lung cancer is smoking. Despite their awareness, about $19.5 \%$ of the medical students in this study keep on smoking.

The finding that smoking makes people more attractive reported by $16.4 \%$ of all students and by $18.7 \%$ of smokers, and to have more friends in $25.1 \%$ and $21.3 \%$ in all students and smokers, respectively, coincides with a previous study (15), that reported insignificant differences between smokers and smokers regarding their belief that smokers have more friends. The ability to form friendships, however, in community like Medina's community substantially depends on social and cultural milieu youths are living in.

This current study has also showed a substantial point about students' favorable behavior toward reducing passive smoking through their support of preventing smoking in public areas. More than two third of smokers (74.6\%) reported that they wanted to quit smoking now or think about quitting in the next 6 months. The majority of students agreed that smoking would not make them look more attractive. This finding indicates that the majority of smokers have intention to quit and will not continue smoking throughout their lives. These findings motivate and encourage the University to increase the number of smoking clinics and activate them and make them more popular and attract the smoker students to come to them and advise them about the possible ways to quit smoking and this is done by getting the official administrators more aware of the size of this issue among University students and their desire and susceptibility to quit smoking.

Strengths of this study include being a university-based with a high response rate from the participated students, and according to our best knowledge, this study is the first to study smoking habit and attitudes among Taibah University students.

Limitations include using a self-administered questionnaire without validation of the collected data through biochemical tests due to financial constraints, which might underestimate the actual prevalence of smoking in the studied students.

This could underestimate the actual prevalence of smoking in the studied students. However, the previous studies $(16,17)$ have reported high reliability of results on teenager smoking when questionnaire are administered anonymous and self-reported. Although, the attitudes of students towards smoking appeared favorable, the complex interaction of many psychosocial, traditional, cultural, and educational factors that influence such attitude was not studied. However, because these factors were beyond the aim and scope of this study, these factors could not be explained in this. The future studies should stress on these factors to explain the reasons behind the given attitudes and beliefs of the studied smokers. 


\section{International Journal of Science and Research (IJSR) \\ ISSN (Online): 2319-7064}

Index Copernicus Value (2015): 78.96 | Impact Factor (2015): 6.391

In summary, this study revealed a considerable high prevalence of smoking among male students in Taibah University, Madinah City, Saudi Arabia. One of the major and important findings of this current study was the positive attitudes of all studied students and smokers in particular towards smoking. This finding has to motivate and encourage the University administrators to increase the number of smoking clinics and activate them and make them more popular and attract the smoker students to utilize helping them to quit smoking.In addition, It would be very helpful to organize an annual smoking campaigns in the various faculties at the university to increase the awareness about the dangerous of smoking.

\section{Acknowledgment}

The authors would like to thank all students participated in this study. They also acknowledge the faculty administrators of the included faculties for their help and cooperation. We would like to express our gratitude to Dr. Khaled Kasim (the supervisor of our research) for his guidance and support in this research.

\section{References}

[1] Nagarajappa R, Daryani H, Sharda AJ, Asawa K, Batra M, Sanadhya S, Ramesh G. Knowledge and attitude towards smoking among Indian students of dentistry. Int Dent J. 2013;63(5):244-8.

[2] MahfouzAA,Shatoor AS, Al-GhamdiBA, Hassanein MA, NaharSh, Farheen A, Gaballah I, Mohamed A, Rabie FM. Tobacco Use among Health Care Workers in Southwestern Saudi Arabia. Biomed Res Int. 2013;2013:960292.

http://www.ncbi.nlm.nih.gov/pmc/articles/PMC377003 6/

[3] World Health Organization: WHO Report on the Global Tobacco Epidemic, 2011. Geneva:WHO;2011.

[4] Fida RH, Abdelmoneim I. Prevalence of smoking among secondary school male students in Jeddah, Saudi Arabia: a survey study. BMC Public Health 2013, 13:1010.

[5] Al-Zalabani A, Kasim K. Prevalence and predictors of adolescents' cigarette smoking in Madinah, Saudi Arabia: a school-based cross-sectional study. BMC Public Health, 2015 15:17

[6] Franco JA, Trullén A, García A, Marrón R, Clemente ML, Rubio E. Tobacco Use of Tobacco Among Young People in Informal Education Settings: a Survey of Behaviors and Opinions, 2004:10-6.

[7] Al-Haqwi A, Tamim H. Knowledge, attitude and practice of tobacco smoking by medical students in Riyadh, Saudi Arabia.AnnThorac Med. 2010;5(3):1458

[8] Al Ghobain MO, Al Moamary MS, Al Shehri SN, AlHajjaj MS. Prevalence and characteristics of cigarette smoking among 16-18 years boys and girls in Saudi Arabia. Ann Thorac Med 2011, 6(3): 137-140.

[9] Al Nohair S. Prevalence of Smoking and its Related Behaviors and Beliefs among Secondary School Students in Riyadh, Saudi Arabia. Int J Health Sci (Qassim) 2011, 5(1): 51-57.
[10] Abdalla AM, Saeed AA, Abdulrahman BM, Al-Kaabba AF, Raat H. Correlates of ever-smoking habit among adolescents in Tabouk, Saudi Arabia. Eastern Mediterranean Health Journal 2009, 15(4):983-992.

[11] Bassiony M: Smoking in Saudi Arabia. Review article. Saudi Med J 2009;30(7):876-881.

[12] Kristjansson AL, Sigfusdottir ID, Allegrante JP, Helgason AR: Social correlates of cigarette smoking among Icelandic adolescents: a population-based cross sectional study. BMC Public Health 2008;8:86.

[13] Damianaki A, kaklamani S, Tsirakis S, Clarke R, Tzanakis N, Makris D: Risk factors for smoking among school adolescents in Greece. Child care Health Dev. 2008;34(3):310-315.

[14] Rudatsikira E, Muula AS, Siziya S: Current use of smokeless tobacco among adolescents in the Republic of Congo.BMC Public Health2010;10:16.

[15] Rudatsikira E, Abdo A, Muula AS. Prevalence and determinants of adolescent tobacco smoking in Addis Ababa, Ethiopia.BMC Public Health. 2007, 7:176.

[16] de Vries H, Mudde A, Leijs I, Charlton A, Vartiainen E, Buijs G. The European Smoking prevention Framework Approach (ESFA): an example of integral prevention. Health Educ Res 2003, 18:611-26.

[17] Brener ND, Kann L, McMannus T, Kinchin SA, Sundberg EC, Ross JG. Reliability of the 1999 youth risk behaviors survey questionnaire. J Adolesc Health 2002, 31:336-342. 